\title{
WWII and XXth Century Wars in the Collective Memory of different generations of Russians: visual methods research
}

\author{
Alexander Rikel ${ }^{1,}{ }^{*}$, Inna Bovina $^{2}$ and Natalia Fedorova $^{1}$ \\ ${ }^{1}$ Lomonosov Moscow State University, Mokhovaya St, 11/9, 125009, Moscow, Russia \\ ${ }^{2}$ MGPPU, Sretenka St., 29, 127051, Moscow, Russia
}

\begin{abstract}
The collective memory about wars is an object of study, as well as the formation and upbringing within the educational process. The category of generation, collective memory, and psychological trauma are considered as central in the framework of the study described here. It is assumed that wars are significant for the formation of psycho-traumatic experience of a generation. Using visual methods, in which people were asked using self-report to evaluate their feelings and emotions when looking at photographs of various wars of the twentieth century, the hypothesis was tested that the role of the Second World War is the most traumatic compared to other wars due to its role, proximity in time and media effect. The conclusions are drawn about the absence of fundamental differences in the memory of World War II by all generations of Russians $(\mathrm{N}=548$ people $)$ in all emotional and traumatic parameters, except for the parameter of feeling of pride in the results of the war.
\end{abstract}

\section{Introduction}

The collective memory of wars is an object of formation within the framework of political, media and educational socialization. The generation is understood within the framework of this study in it's socio-psychological meaning. This interpretation is opposed to biological, genealogical, psychogenetic or demographic understanding and goes back to the classical definition of K. Mannheim, who defined the generation with the help of jointly experienced in a sensitive period of experience, which later transformed into collectively similar reactions based on formed values [1]. This interpretation essentially includes a historical, sociological, culturological and, as a result, a socio-psychological approach to understanding the generation, and it is this approach that is used by most authors to illustrate the value differences and behavioral features of different age groups [2, 3, 4, 5, 6]. Despite the differences attributed to generational groups, the terminological framework of the generation itself remains blurred, conceptual boundaries in various classifications are conditional, and the methods of studying the system-forming factors of this large social group are not always objective $[6,7,8]$.

\footnotetext{
* Corresponding author: a.m.rikel@gmail.com
} 
At the same time, based on the socio-psychological criterion highlighted above, various classifications of generations are considered according to the fact of significant sociohistorical and cultural-technological events that occurred during the period of active socialization of the generation. In the study described here, the Howe and Strauss typology was used as the basic classification. This classification, being initially pop-scientific, cannot be the standard of valid operationalization, however, it has firmly entered the scientific research tradition as the most wide spread [9].

If representatives of one generation become witnesses of a significant historical event, then the collective memory of such events can be considered as the most important construct that unites generations [10]. Group nature is passed from generation to generation, through communication with relatives and friends, under the influence of the media, etc. Collective memory enables its bearer to identify with the group, helps her to realize her unity and originality, objective manifestations of collective memory can be both positive and negative. At the same time, only significant events that are relevant within the framework of joint communication become the content of collective memory, which makes it important for generational discourse [11].

Collective memory studies are often carried out using intergenerational methodology, while the object of studying the collective memory of generations is traumatic events $[12,13$, 14]. Traumatic changes can be considered collective, when entire ethnic and national groups are traumatized as a result of any event. Such events can be revolutions, changes in the social system, mass migrations, economic crises, wars, etc. In the context of this study it is important to note that not only direct participants in traumatic actions, but also representatives of subsequent generations are subject of mental trauma. In some cases, an overwhelming psychotraumatic experience can lead to a generational conflict, when generations understand and relate to past events in different ways [12].

The collective memory of the war, following M. Halbwachs, is often interpreted as shared ideas about the historical past, that is, analyzed in the mainstream of cognitive social psychology. At the same time, the actualization of these ideas and memories is carried out with the help of various symbols. Collective memory is symbolic in nature and purely eidetic, as it is saturated with various images [15].

This effect is enhanced by intergenerational differences in the way information is processed. Thus, the obvious dominance of visual culture, implying the predominance of visual images over text in the cultural space, has long become a common place in the works of cultural studies $[16,17,18]$. In the mainstream of sociology, a separate direction appears that deals with the study of social processes and phenomena through the visual sociology as a prism of visual images and representations [19]. Photographs and video materials cease to play only an accompanying function in cognition of the surrounding world, but more and more become a source of both information and the feelings that cause them. This is undoubtedly promoted by the development of digital technologies, new media, social networks, as well as the environment of urban cultural artefacts (outdoor advertising, urban design, street art, etc.); tutorials are also beginning to rely on images (infographics, presentations, memes and other graphic principles). This allows a number of specialists to talk about the widespread distribution of so-called "clip mentality" among the younger generation, when the priority in the perception and processing of information is given, rather, to conveniently structured (in particular, visual) information [20, 21].

A separate place in the research of collective memory and associated psychotraumas is occupied by the research of wars [11]. Wars are examples of both traumatic and heroic events that are reflected in the collective memory, and therefore deeply rooted in it [22]. Symbolization of such an event as war can take place in the mainstream of works of culture and media, as well as within the framework of urban memorialization (monuments, etc.). So, places of memory serve as "fulcrum" for consolidating information about the past, preventing 
the appearance of "gaps" in memory [10]. In this context, it is interesting to distinguish between the memorialization of heroic and non-heroic military conflicts (for example, the Great Patriotic War and the Afghan War). In the same way, the complexity of the attitude of Russians to the events of WWI can be compared with a similar ambiguity in the attitude of the Germans to the events of WWII: the non-heroic past associated with these events among representatives of the two nations makes the descendants refuse to memorize these events, contributes to the displacement of the symbols of these wars from the collective memory.

Collective memory research, as noted above, as a rule, affects its cognitive aspects, which also concerns the research of wars. In a recent study [11], on the one hand, the significance of the attitude of all age groups to the events of the WWII is described, and on the other hand, the contradiction and complexity of this attitude is shown: if the assessments and impressions of the older generation are sufficiently consistent, then the attitude of young people is characterized by greater skepticism and doubts about the traditions associated with it.

In the logic of the study of mental trauma, it was revealed that the WWII should be less traumatic due to the vivid heroic feelings associated with it, which, unlike the same WWI or the Afghan war, were caused by the victory achieved and the feeling of their own righteousness among its participants. At the same time, the very role of the WWII in the collective memory of modern Russians is difficult to overestimate: in a recent study [23], references to the WWII took a leading position in the core of social perceptions along with the Revolution of 1917 and Space exploration while talking about events in Russia in the 20th century. The WWII is not less often mentioned among the events about which "children should know and remember." It is significant that it was the mentions of the WWII in this study that united various generational groups, which representatives felt "pride" talking about this war.

\section{Materials and Methods}

The problem of the research is the insufficient study of only cognitive aspects (memories, ideas) when analyzing the collective memory of the wars of the XX century in the context of possible psychotraumas and the lack of data on the emotional component of collective memory. The novelty of the research described here is (1) the use of the original visual method as a projective method for studying emotional and psychotraumatic experience, as well as (2) comparison of this experience in the context of the wars of the XXth century, in which Russia took an active part. The object of the study is representatives of different generations of modern Russia, and the subject is the peculiarities of intergenerational differences in the emotional component of collective memory regarding the WWII and the differences in these reactions within the framework of various wars of the XX century. The presence of a vivid emotional reaction, which could testify to deep emotional experiences, was interpreted as one of the indicators of psychotrauma. The main hypothesis was the assumption that these emotional reactions (and, as a consequence, psychotrauma) will be much brighter in terms of the attitude of the Second World War in comparison with other wars of the XX century, which is easily explained by the significant involvement due to the involved relatives and friends, as well as efforts in the State policy to preserve the collective memory of the War.

The projective technique used in this study belongs to the group of visual methods, which involve studying not the reality presented in the image (photograph), but also the features of the image of this reality, constructed by the observer (respondent) [24]. In this case, the technique belongs to the class of instruments where the presented material plays the role of a kind of trigger for the initiation of feelings and experiences of the subjects [25]. 
The study was conducted in two stages. At the first stage, an expert group (historians) was involved, and visual stimuli (photographs) were selected. At the second stage, the main, substantive part of the study took place.

At the first stage, it was necessary to assess how easily visual stimuli can be attributed to a certain historical period, or rather, to specific military actions. As a stimulus material, photographs of 3 wars in which Russia participated during the XXth century were chosen: WWI, WWII, the Chechen War (the so-called I and II Chechen wars are not divided in the context of the study). The Afghan war was not chosen due to the specific landscape conditions, fundamentally different from the other two wars. Visual stimuli were black-andwhite photographs selected according to two criteria: (1) a historical event: WWI, WWII or the Chechen War (hereinafter - CW); (2) the emotional reaction that the photograph supposedly should have caused: negative (battles, active hostilities) (hereinafter - "-"), neutral (front-line photographs, the life of soldiers outside the battle) (hereinafter - "0"), positive (what some joyful events, leisure, entertainment and recreation at the front) (hereinafter "+"). The photographs were selected based on the presence of male soldiers, the absence of women and children, and animals. As a result, 9 groups of photographs were identified based on the first and second criteria. Experts (23 specialists with higher history education) were asked to rate 46 photographs in random order. They had to write in free form what time period each photo belongs to and assess the degree of confidence in their answer from 1 to 5 points. On the basis of their assessments, 10 visual stimuli were selected with the highest coefficient of agreement of responses (at least $73.9 \%$ of agreement).

At the second stage of the study, the respondents were asked to evaluate the previously selected visual stimuli (photographs), and they were not told to what time period they belonged. The following text acted as an instruction: Please look at the photo below. How does it make you feel? Your attitude to the events that happened to the heroes of the photograph in a broader sense is important for us. When describing a photograph, please concentrate mainly on your emotions and feelings.

The sample consisted of 589 people (among them representatives of the so-called Z Gen (14-18 years old) - 67 people, Gen Y (19-32 years old) - 326 people, Gen X (33-52 years old) - 148 people, Gen BB (54-63 years) - 48 people. The gender (58\% women, $42 \%$ men) and education (43\% higher, 38\% - another type of education) factors were not analyzed.

To process the results, a computer program for the primary text was used, which prepared the response texts of the respondents, bringing word forms to the canonical form by discarding the endings (primary automated content analysis). Further, from the obtained categories of word forms, words were singled out indicating feelings and emotions, which after that became the basis for content analysis of the text. The reliability of the categorization was checked by an expert assessment (coefficient of reliability "Pi" Scott criterion =0.9) (see Table 1 - Content analysis of emotions). Next, a frequency analysis was performed. The Mann-Whitney test (SPSS program) was used to test the significance of differences between the severity of certain feelings about war in specific generations and to compare data on WWII and other wars within the sample.

\section{Results}

The answers to the questions varied among different respondents, moreover, different generations used a different number of word forms (which described important categories of emotions and feelings in the study). Smaller "answers" can be explained by insufficient computer training of representatives of the BB generation (over 54 years old) and a kind of "clip-like" thinking of representatives of Z Gen (under 17 years old) (see Table 1).

Despite significant differences (up to 5 times) in the number of words used, all generations use at least $49 \%$ of the so-called "important categories" identified in the study 
when describing their feelings and emotions (that is, words and word forms related to the description of feelings and emotions). Since the total number of words was used, it can be concluded that the percentage of significant words is large. Next, 70 categories were identified that describe emotions and feelings, which formed the basis of a highlighted categorical grid containing a description of feelings and emotions: (A) Negative emotions and feelings ('active', those that are associated with aggression towards another, for example, hatred, disgust, rage; 'passive', that is, not associated with aggression, for example, sadness, sadness, pain); (A1) Manifestations of fear (fear, anxiety, terror); (B) Positive emotions and feelings (inspiration, confidence; hope, peace, relief); (B1) Indicators of pride (pride, awe, touching); (B2) Expressions of empathy, empathy for others, gratitude; (C) Attribution and description of the emotions and feelings of the warriors; (D) Description of neutral emotions (indifference, apathy); (E) Other emotions.

Table 1. Distribution of answers depending on the age of the study participants.

\begin{tabular}{|c|c|c|}
\hline Generation & Mean number of words used (pes) & $\begin{array}{c}\text { The Amount of words, classified } \\
\text { as important categories of } \\
\text { emotions and feelings (\%) }\end{array}$ \\
\hline BB & 386 & 49.9 \\
\hline X & 1519 & 52.3 \\
\hline Y & 3544 & 48.9 \\
\hline Z & 862 & 65.0 \\
\hline
\end{tabular}

Table 2. Representation of answer categories among different generations (\%).

\begin{tabular}{|c|c|c|c|c|c|}
\hline \multirow{2}{*}{ Generation } & \multicolumn{5}{|c|}{ Emotions } \\
\cline { 2 - 6 } & Fear & Empathy & Pride & $\begin{array}{c}\text { Feelings } \\
\text { Attribution }\end{array}$ & Neutral \\
\hline BB & 6 & 4 & 0.5 & 0.5 & 0.5 \\
\hline X & 3 & 2 & 1 & 1 & 0 \\
\hline Y & 10 & 3 & 1.5 & 1 & 1 \\
\hline Z & 6 & 1 & 2 & 3 & 1.5 \\
\hline
\end{tabular}

Table 2 shows the representation of the selected categories in the responses of respondents of different generations, regardless of specific wars of the XX century. To analyze the differences between the identified categories, we used one-way ANOVA and the MannWhitney test for independent samples. The most common emotion is 'Fear', which also shows the most significant differences between generational groups. Among Gen X emotions are overall less pronounced than in other generations $(\mathrm{p}=0.01)$. The expressiveness of 'Empathy' decreases with decreasing age of the generation, while 'Pride', on the contrary, increases. In general, feelings and emotions are significantly more often represented in $\mathrm{Y}$ than in X Gen $(\mathrm{p}=0.033)$.

Statistical analysis (see Table 3) using the Mann-Whitney test, the number of categories describing feelings in general, and more specifically, feelings of pride, is higher when describing WWII than when describing other wars $(\mathrm{p}=0.01)$. The WWI prevails in the 'neutral' category, which may indicate a certain detachment of respondents from the events of WWI, which reduces the number of vivid feelings and emotions. This assumption is supported by the least severity of the 'Fear' category. The 'Empathy category is expressed in the same way in all three cases (there are no statistically significant differences between the groups). When describing CW, unlike WWI and WWII, the least expressed positive feelings, the most common category is 'Fear'. 
Table 3. Representation of emotional categories in the description of different wars (\%).

\begin{tabular}{|l|c|c|c|}
\hline \multirow{2}{*}{\multicolumn{1}{c|}{ Emotions }} & \multicolumn{3}{c|}{ War } \\
\cline { 2 - 4 } & \multirow{2}{*}{ WWI } & WWII & CW \\
\hline Feelings Attribution & 6.2 & 9 & 9.9 \\
\hline Pride & 4.2 & 21.3 & 7 \\
\hline Neutral Emotions & 8 & 2.3 & 4.2 \\
\hline Fear & 14.6 & 22 & 30.3 \\
\hline Empathy & 10.7 & 7.6 & 11.6 \\
\hline
\end{tabular}

\section{Discussion and Conclusion}

1. The most common feeling that arises when describing war among all generations is fear, which seems natural both in the very logic of war and in the current geopolitical situation. $\mathrm{CW}$ took place precisely at the stage of active socialization of Gen Y, at the same time the war in Afghanistan did not take place on the territory of the USSR and mostly affected the direct participants in the war and their relatives. Earlier [13] it was revealed that events for a person that are significant for the formation of collective memory are exactly those that were actual during his youth and further perception of events in a political and social context occurs through the prism of events that happened during his youth. Perhaps that is why for the generation of 32-54 year old, war is not an event that causes such an emotional reaction. During their youth, there were no major armed conflicts. Within the framework of another interpretation, collective memory is passed from generation to generation, and almost all parents and relatives of respondents over 54 years old (for those who were not a direct witness of the Second World War) were its counterparts. That is, the collective memory was passed on to this generation from the direct participants of the events, which suggests that the WWII can cause strong feelings in them.

2. At the same time, the lower 'Empathy' among the younger generation correlates with the data obtained in previous studies on the prevalence of the strategy of competition over cooperation in interpersonal relations among Gen Y [26], which can also be explained by the conditions of their socialization in full market competitive environment.

3. Comparison of the WWII with other wars shows two interesting results. This War is a source of pride for all generations. The predominance of pride associated with the WWII is quite logical: its result was the country's victory, while WWI did not end in victory for the Russian Empire, and the results of the WWII are not so clear-cut in public opinion. This correlates with the findings of researchers who call the withdrawal of the invincible sides of wars into the 'subconsciousness' of society as a 'blind spot of memory'. In addition, in recent years, the state has been demonstrating active propaganda dedicated to the WWII: every year massive and colorful parades, online and offline campaigns dedicated to the Victory, are organized.

4. Another, not quite expected result, which contradicts the initial hypothesis of the study, shows that WWII is not a psychotrauma for the studied sample, since its perception in terms of the representation of negative emotions does not differ from the perception of other wars. A logical version of the explanation of this fact can be the natural prevalence of negative emotions when observing images of war. These data have been repeatedly confirmed in experiments on persuasive communication, when the emotions of fear turned out to be most vivid precisely when using visual images. With this interpretation, the lack of differentiation of wars is logical and natural. At the same time, the most logical model of interpretation for the authors of the study (which does not contradict the schemes described above) is that the Russian population, actively experiencing pride (that is, positive emotions) for the results of the WWII, at the same time does not differentiate this war in terms of the perception of its 
negative component. The state information policy is not logically aimed at influencing feelings in this part of the emotional spectrum, which makes it quite logical to 'equalize' negative feelings from the WWII with other wars.

\section{Possible limitations of conclusions}

1. Limitations of the toolkit of visual methods for analyzing emotions and experiences in line with collective memory (we consider this method as one of the possible tools and, of course, does not pretend to be complete).

2. Possible interpretation of the results obtained as age-related, not generational, that is, the absence of generational identification in the study design and measurement tools (offset by the sample size).

\section{References}

1. K. Mannheim, Essays on the sociology of knowledge (Routledge, London, New York, 1997)

2. C. Gilleard, P. Higgs, Contexts of Ageing: Class, cohort and community (Polity Press, Cambridge, 2005).

3. Ju.A. Levada, Sochinenija: izbrannoe: sociologicheskie ocherki 2000-2005 (Izdatel' Karpov E.V., Moscow, 2011)

4. A.V. Miklyaeva, M.I. Postnikova, Social Psychology and Society 2(10), 114-126 (2019) doi:10.17759/sps.2019100209

5. A.M. Rikel', Social Psychology and Society 2(10), 9-18 (2019) doi:10.17759/sps.2019100202

6. J. White, The British Journal of Sociology 2(64), 216-247 (2013) https://doi.org/10.1111/1468-4446.12015

7. V. Pishchik, A. Belousova, L. Ryumshina, EDULEARN18 Proceedings 10th International Conference on Education and New Learning Technologies (Palma, Spain, 2018) doi: 10.21125/edulearn.2018.0524

8. J.M. Twenge, S.M. Campbell, Perspectives on Psychological Science 5(1), 81-88 (2010) $10.1177 / 1745691609357015$

9. A. Joshi, J., Dencker, G. Franz, Research in Organizational Behavior 31, 177-205 (2011) doi:10.1016/j.riob.2011.10.002

10. P. Nora, Pokolenie kak mesto pamjati. Novoe lit. obozr. 30, 48-72 (1998)

11. T. Emelyanova, A. Misharina, Izv. Saratov Univ. (N. S.), Ser. Educational Acmeology. Developmental Psychology 8.4(32), 334-340 (2019) DOI: https://doi.org/10.18500/2304-9790-2019-8-4-334-340

12. W. Bohleber, Psyche-Zeitschrift für Psychoanalyse und ihre Anwendungen 54, 797-839 (2000)

13. H. Schuman, J. Scott, American Sociological Review 54, 359-381 (1989)

14. C. Kidron, D. Kotliar, L. Kirmayer, Social Science \& Medicine 239, 112524 (2019) https://doi.org/10.1016/j.socscimed.2019.112524

15. P. Riceur, Memory, History, Forgetting (University of Chicago Press, 2004)

16. D. Harper, Visual 17(1), 13-26 https://doi.org/10.1080/14725860220137345 
17. A. Dontsov, A. Drozdova, Y. Gritskov, Procedia - Social and Behavioral Sciences 86 (2013) doi:10.1016/j.sbspro.2013.08.527

18. G.V. Kokturk, Procedia - Social and Behavioral Sciences 70, 1200-1203 (2013) https://doi.org/10.1016/j.sbspro.2013.01.177

19. P. Sztompka, International Encyclopedia of the Social \& Behavioral Sciences (2015) Doi 10.1016/B978-0-08-097086-8.32194-8

20. A. Alekhin, A. Grekova, Clinical Psychology and Special Education 8(1), 162-176 (2019) doi: 10.17759/psycljn.2019080110

21. C. Jones, R. Ramanau, S. Cross, G. Healing, Computers \& Education 54(3), 722-732 (2010) http://dx.doi.org/10.1016/j.compedu.2009.09.022

22. T. Emel'janova, T. Drobisheva, Humanitarian Knowledge Horizons 5, 71-85 (2017) Doi: http://dx.doi.org/10.17805/ggz.2017.5.6

23. V. Baranova, A. Dontsov, Social Psychology and Society 10(2), 29-46 (2019) doi:10.17759/sps.2019100204

24. G. Rose, Visual Methodologies. An Introduction to Researching with Visual Materials (Sage, London, 2007)

25. O. Mel'nikova, A. Mezentseva, Social Psychology and Society 9(3), 42-52 (2018) doi:10.17759/sps.2018090305

26. A. Rikel', Social Psychology and Society 11(3), 135-148 (2020) DOI: https://doi.org/10.17759/sps.2020110309 